\title{
Estimation of Level of Service for Urban Arterial Road of Ahmedabad City
}

\author{
Supreet Singh Nogi ${ }^{1}$, Roopam Gadhvi ${ }^{2}$, Ashu Meena ${ }^{3}$, Assistant Professor Arpit Sharma ${ }^{4}$ \\ B.E Student, Civil Engineering Department, Indus University, Ahmedabad ${ }^{1,2,3}$ \\ Assistant Professor, Civil Engineering Department, Indus University, Ahmedabad ${ }^{4}$ \\ Indus Institute of Technology \& Engineering, Indus University ${ }^{1,2,3,4}$ \\ Email: supreetnogi@gmail.com ${ }^{1}$, arpitsharmacivil@gmail.com ${ }^{2}$
}

\begin{abstract}
Vehicle volumes have increased significantly in the last decade due to the change of the economics of the middle-class families. In Ahmedabad city, most of arterial roads are congested. An attempt has been made to quantify congestion with speed and volume to capacity ratio. There is a need for defining traffic congestion on rational bases and use that for measurement LOS (Level of Service) of roads. A significant effort has been made in order to study the Traffic Volume of Visat-Gandhinagar highway, Ahmedabad. The largest city of Gujarat, Ahmedabad itself attracts a lot of vehicular population. The objective of the study is to analyze the prevailing traffic conditions on the Visat-Gandhinagar highway. Traffic Volume study is carried out on selected stretch at ONGC Circle to Tapovan circle and existing level of service is calculated. The basic problem arises during the peak hours of the day when the traffic volume is highest on the road.
\end{abstract}

Index Terms-Level of Service; Heterogeneous Traffic; Urban Arterial Road

\section{INTRODUCTION}

Transportation planning is the field involved with the siting of transportation facilities. The safe and time efficient movement of the people and goods is dependent on Traffic flow, which is directly connected to the traffic characteristics. The three main parameters of a traffic flow are volume, speed and density. It is essential to convert the flow of the different vehicle classes into a standard vehicle class known as passenger car unit. Traffic volume studies are conducted to determine the number, movements, and classifications of roadway vehicles at a given location. The heterogeneous traffic flow is defined as a region of high density and low average velocity of vehicles and the flow of heterogeneous traffic on urban roads are extremely composite and the existing models cannot be employed to define the Level of Service (LOS) of urban roads whereas, homogeneous traffic has strict lane discipline and has traffic entity types whose characteristics do not vary much.

\section{PROBLEM DEFINITION}

- Population increase in urban areas.

- Vast urban automobile growth.

- Increase in traffic and congestion due to heterogeneous traffic.

- Less road safety.

- Need for estimation of level of service for heterogeneous traffic.

\section{BASIC DEFINITIONS}

\subsection{Capacity}

It is the maximum hourly volume (vehicles per hour) at which vehicles can reasonably be expected to traverse a point or a uniform section of a lane or roadway under the prevailing roadway, traffic and control conditions. Capacity of urban road is also a function of the road-side conditions, e.g. parking, commercial activities, frontage access etc.

\subsection{Level of Service(LOS)}

Level of Service is a general term of expressing the traffic performance of a highway. LOS represents the qualitative measure of the road section. For a given road facility, capacity can be constant whereas actual flow will be a varying parameter depending on the time of the day. To relate the traffic service quality to a given flow rate of traffic is the main objective of LOS. It is a term that designates a range of operating conditions on a particular type of facility. Speed has been considered as the principal factor affecting the LOS of an urban road segment under ideal conditions. Stream speed has been considered as the basic parameter for the estimation of LOS in the present study. As mentioned earlier, the data on free flow speed of vehicles for selected road sections can be collected through videography or through any other techniques like pneumatic tube or infrared methods. In this study, videography technique is been used to collect the data, the camera was been placed at a distant and elevated point from where a clear view of the stretch of selected study area was visible. 


\section{Available online at www.ijrat.org}

\section{OBJECTIVES OF THE STUDY}

study:

Following are the objectives of the present

(1) To identify the traffic characteristics of study area.

(2) To explore the present traffic condition.

(3) To check existing, operating service condition of a roadway section.

(4) To relate the resultant LOS criteria and suggested LOS criteria by INDO-HCM.

(5) To determine observed speed ranges and V/C (i.e. Volume/Capacity) ratio for existing traffic.

\subsection{Background}

Level of Service is a general term of expressing the traffic LOS "A" to LOS " $F$ ". LOS A represents the highest quality of service where motorists are able to travel at their desired speed. Where as LOS F represents congested flow where traffic demand exceeds capacity.

\section{METHODOLOGY}

The present study aims to analyze and estimate new Level of Service for urban road. It is essential to develop an appropriate methodology for accurate estimation of Level of service.Following parameters are considered for determing LOS for observed traffic condition.

- $\quad$ Speed

- Flow

- Capacity

- V/C (Volume/Capacity) ratio

Following methodology is used for determining Level of Service.

(1) Selecting study area.

(2) Classify urban street type and class.

(3) Calculating flow, speed and capacity.

(4) Determing V/C ratio.

(5) Analyzing data collected for determing LOS.

(6) Comparison of existing LOS criteria and observed LOS criteria.

\section{STUDY AREA AND DATA COLLECTION}

\subsection{Study Area}

Located on the banks of river Sabarmati, Ahmedabad is the largest city in the whole state of Gujarat. Ahmedabad lies at $23.03^{\circ} \mathrm{N} 72.58^{\circ} \mathrm{E}$ in western India at 53 meters (174 ft.) above sea level on bank of Sabarmati River, in north-central Gujrat. It covers an area of $464 \mathrm{~km}^{2}$. Ahmedabad is the sixth largest city (Pop. 6.5 million) in India, and it's India's first UNESCO World Heritage City.A six lane divided arterial road of length $2.5 \mathrm{~km}$ is selected as study stretch. The stretch selected for data collection and its analysis starts from ONGC circle and ends at Tapovan circle on Visat-Gandhinagar highway.

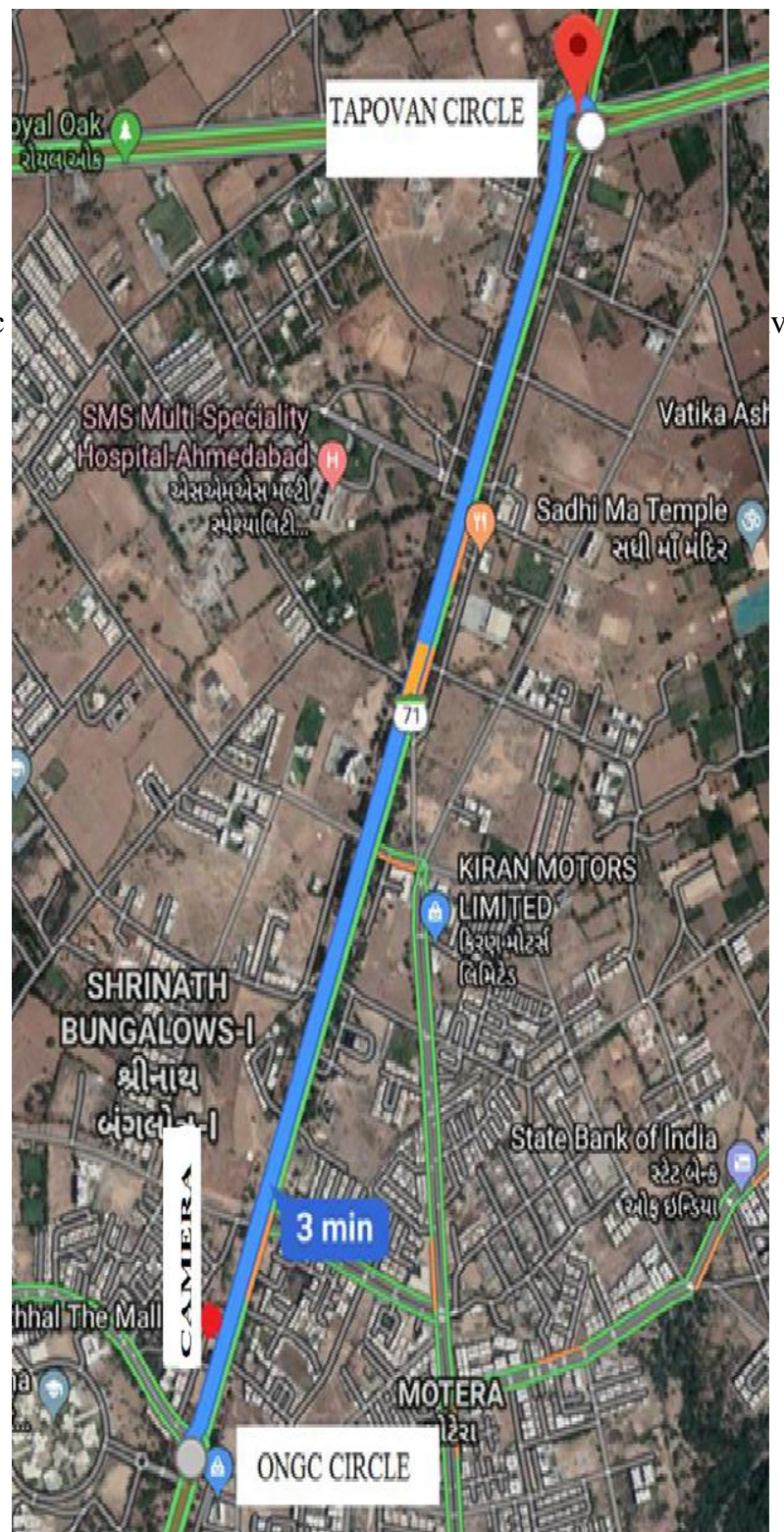

Fig 1. Satellite image of ONGC Circle - Tapovan Circle Stretch 


\section{Available online at www.ijrat.org}

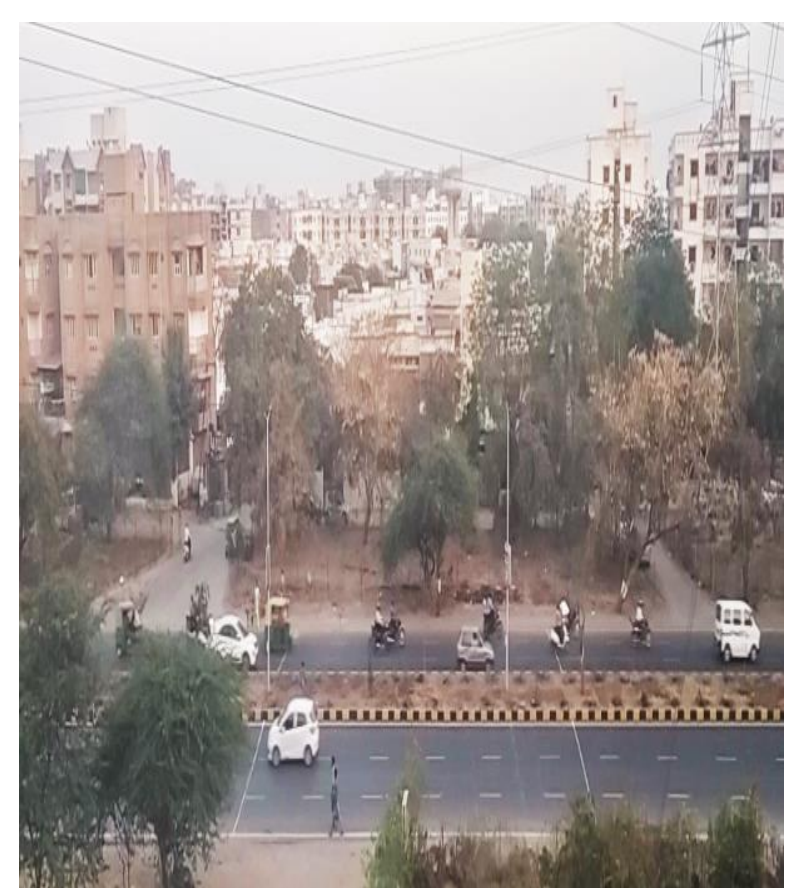

Fig 2. Site Images for Peak hour $(17: 00-19: 00)$

\subsection{Data Collection}

To determine the criteria for LOS, Road inventory surveys were carried out for collecting data regarding geometry of road which consists number of lanes, shoulder and its type, lane markings etc. Traffic surveys are conducted on weekdays during morning and evening for peak hour data and afternoon for offpeak hour data.Videography is taken as primary source of data collection. Purposeful Data are collected using videography technique for volume and speed. Then the data are extracted in the laboratory. Following parameters will be determined from the data extraction.

- Traffic composition

- Volume of Traffic

- Spot speed of vehicles

- Roadway capacity

Table 1. Road Inventory Data

\begin{tabular}{|c|c|}
\hline Road Type & $\begin{array}{c}\text { Six-Lane Divided } \\
\text { Arterial Road }\end{array}$ \\
\hline Stretch & $\begin{array}{c}\text { ONGC Circle to } \\
\text { Tapovan Circle } \\
(2.5 \mathrm{~km})\end{array}$ \\
\hline $\begin{array}{c}\text { Carriageway Width- } \\
\text { One Way(m) }\end{array}$ & 9.55 \\
\hline Shoulder Type & Unpaved \\
\hline Shoulder Width(m) & 2.5 \\
\hline Footpath & - \\
\hline Median Width(m) & 5.3 \\
\hline Road Condition & Good \\
\hline
\end{tabular}

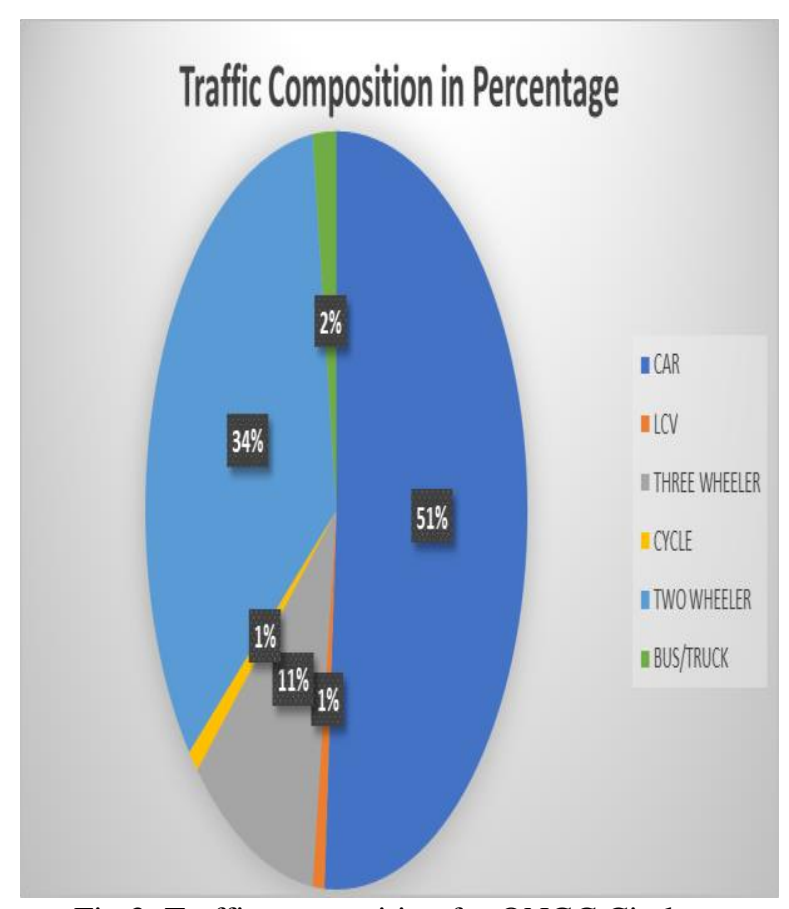

Fig 3. Traffic composition for ONGC Circle to Tapovan Circle

It was observed that traffic composition of two wheelers, auto and car for ONGC Circle to Tapovan Circle is 51\%, $11 \%$ and $34 \%$ respectively.

Table 2. Traffic Volume Count

\begin{tabular}{|c|c|c|}
\hline Time & $\begin{array}{c}\text { ONGC Circle } \\
\text { to Tapovan } \\
\text { Circle PCU/hr } \\
\text { (Towards } \\
\text { Tapovan) }\end{array}$ & $\begin{array}{c}\text { ONGC Circle } \\
\text { to Tapovan } \\
\text { Circle PCU/hr } \\
\text { (Towards } \\
\text { ONGC) }\end{array}$ \\
\hline $9: 00-10: 00$ & 1831 & 1767 \\
\hline $10: 00-11: 00$ & 1800 & 1874 \\
\hline $17: 00-18: 00$ & 1629 & 1826 \\
\hline $18: 00-19: 00$ & 2218 & 2320 \\
\hline
\end{tabular}

The above table shows the traffic volume count of the Peak hours in PCU/hr.

Table 3. Observed Capacity

\begin{tabular}{|c|c|c|}
\hline Time & $\begin{array}{c}\text { ONGC Circle } \\
\text { to Tapovan } \\
\text { Circle Km/hr } \\
\text { (Towards } \\
\text { Tapovan) }\end{array}$ & $\begin{array}{c}\text { ONGC Circle } \\
\text { to Tapovan } \\
\text { Circle Km/hr } \\
\text { (Towards } \\
\text { ONGC) }\end{array}$ \\
\hline $9: 00-10: 00$ & 42.68 & 39.59 \\
\hline $10: 00-11: 00$ & 41.98 & 40.16 \\
\hline $17: 00-18: 00$ & 39.41 & 40.48 \\
\hline $18: 00-19: 00$ & 34.84 & 35.39 \\
\hline
\end{tabular}

The above table shows the average speed of vehicles during peak hour. 


\section{Available online at www.ijrat.org}

\section{OBSERVED PERCENTILE SPEED}

After the collection of data, the spot speed values are organized to their magnitudes. The interval speed of $5 \mathrm{kmph}$ is selected and grouping of data is done. The cumulative frequency distribution curve is plotted from the data of different speed ranges. The cumulative frequency distribution curve is a plot of speed versus the percent of vehicles traveling at or below the designated speed. The median speed, 15th percentile speed, 85th percentile and 98th percentile speed are determined from cumulative frequency distribution curve. The points on graphs of Y-axis are taken and are intersected to frequency curve and the corresponding percentile speeds are plotted on X-axis. It gives a clarification of the high and low speeds observed in the study area. The analysis of various speeds from ONGC Circle to Tapovan Circle is shown in Table 4. It is described from table that the 98th percentile, 85th percentile and 15th percentile of observed vehicles are $62 \mathrm{Km} / \mathrm{hr}$, $55 \mathrm{Km} / \mathrm{hr}$ and 32.5 $\mathrm{Km} / \mathrm{hr}$ respectively. Fig 4 shows the cumilative frequency curve ploted between Percentile and Speed in $\mathrm{Km} / \mathrm{hr}$.

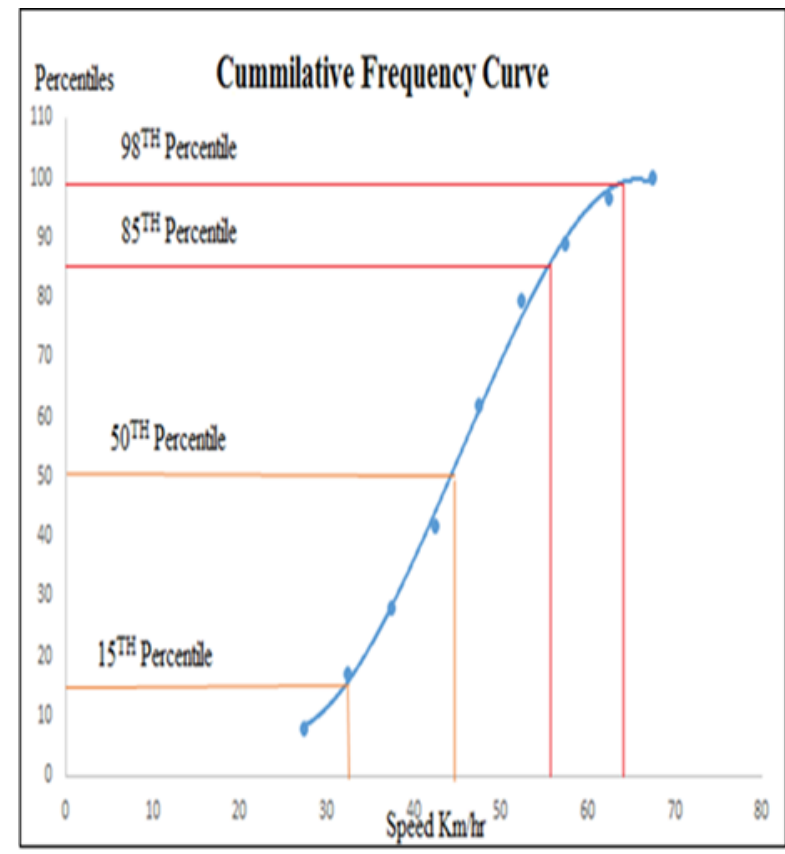

Fig 4. Observed Percentile Speed

Table 4. Summary of Observed Percentile for ONGC Circle to Tapovan Circle

\begin{tabular}{|c|c|}
\hline PARAMETER & VALUE \\
\hline MEDIAN SPEED & $44 \mathrm{Km} / \mathrm{hr}$ \\
\hline $\begin{array}{c}\text { 15TH PERCENTILE } \\
\text { SPEED }\end{array}$ & $32.5 \mathrm{Km} / \mathrm{hr}$ \\
\hline $\begin{array}{c}\text { 85TH PERCENTILE } \\
\text { SPEED }\end{array}$ & $55 \mathrm{Km} / \mathrm{hr}$ \\
\hline $\begin{array}{c}\text { 98TH PERCENTILE } \\
\text { SPEED }\end{array}$ & $62 \mathrm{~km} / \mathrm{hr}$ \\
\hline
\end{tabular}

\section{SPEED-FLOW RELATIONSHIP}

The Speed-Flow relationship is established using the data collected in peak and off-peak hour Speed determined for 5 minute interval is taken for plotting the points on Y-axis. The 5 minutes traffic volume is converted into flow i.e. PCU/hr and is plotted on Xaxis. The speed-flow relationship determined for ONGC Circle to Tapovan Circle are shown in Fig 5 and Fig 6 where Fig 5 gives the details of speed-flow relationship developed for ONGC Circle to Tapovan Circle approach. The upper curve has the maximum limit of 3500 for flow and minimum limit of 912 for flow beyond which the trend line is extended and reaches the maximum value of speed to about 61 $\mathrm{Km} / \mathrm{hr}$. The lower curve has the maximum value of 3500 and minimum value of 1476 up to which the established relation is valid. The trend line for lower curve has also been extended and it reaches the value of speed nearly $0 \mathrm{Km} / \mathrm{hr}$. Similarly the relationship is established for all the stretches individually for each direction.

Capacity standards are normally fixed in relation to level of service. Capacity is the maximum hourly volume (PCU/hr) at which vehicles can reasonably expected to traverse a point or uniform section of a lane or roadway during a given time under the prevailing roadway, traffic and control condition. The highest traffic volume observed on the mid-block of the selected stretches is considered as capacity of the road. The Observed Capacity for the stretch towards Tapovan Circle is $3500 \mathrm{PCU} / \mathrm{hr}$ and for the stretch towards ONGC Circle is $3250 \mathrm{PCU} / \mathrm{hr}$ which makes a total capacity of $6750 \mathrm{PCU} / \mathrm{hr}$.

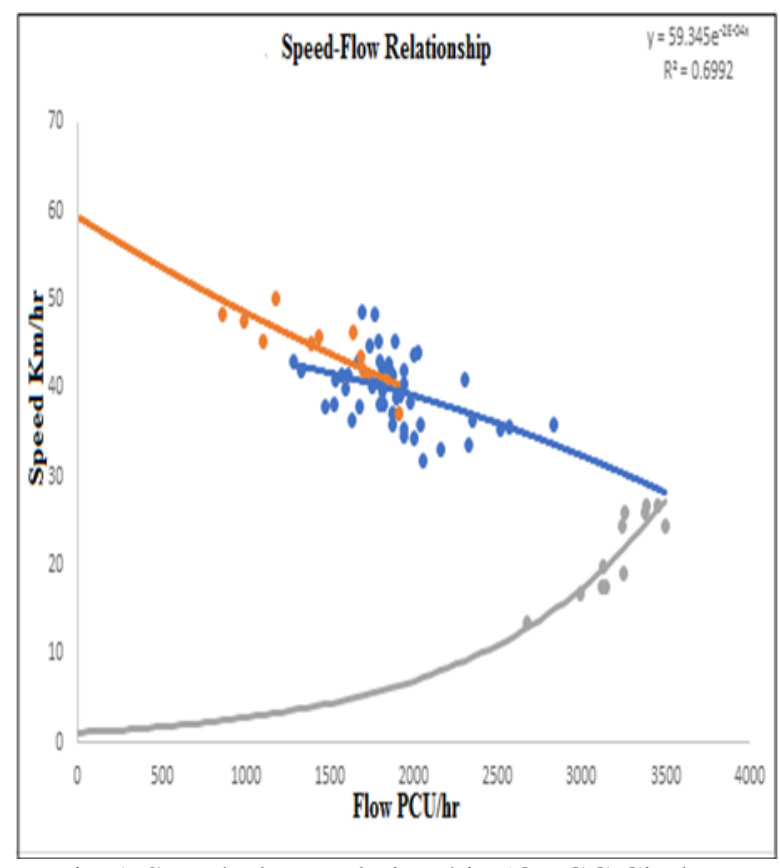

Fig 5. Speed Flow Relationship (ONGC Circle to Tapovan Circle) 


\section{Available online at www.ijrat.org}

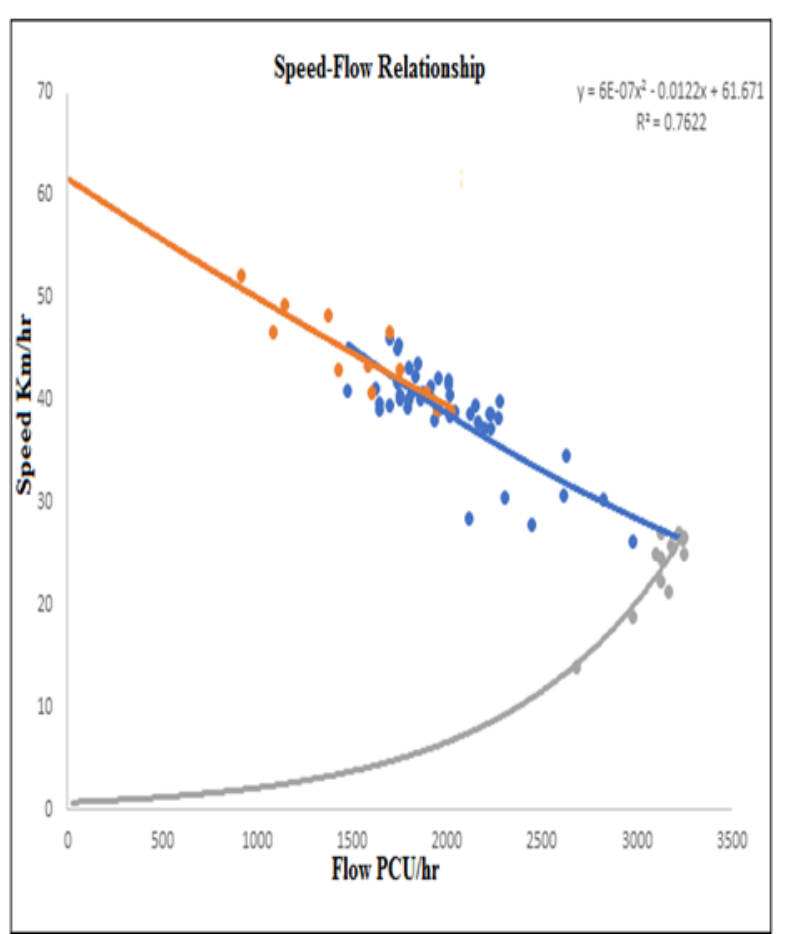

Fig 6. Speed Flow Relationship (Tapovan Circle to ONGC Circle)

Table 5. Observed Capacity

\begin{tabular}{|c|c|c|}
\hline Stretch & \multicolumn{2}{|c|}{$\begin{array}{c}\text { ONGC Circle to } \\
\text { Tapovan Circle }\end{array}$} \\
\hline Direction & $\begin{array}{c}\text { Towards } \\
\text { Tapovan } \\
\text { Circle }\end{array}$ & $\begin{array}{c}\text { Towards } \\
\text { ONGC } \\
\text { Circle }\end{array}$ \\
\hline $\begin{array}{c}\text { Capacity PCU/hr } \\
\text { (One way) }\end{array}$ & 3500 & 3250 \\
\hline $\begin{array}{c}\text { Capacity PCU/hr } \\
\text { (Two way) }\end{array}$ & \multicolumn{2}{|c|}{6750} \\
\hline
\end{tabular}

Table shows observed capacity of selected stretches. The observed capacity of ONGC Circle to Tapovan Circle is $6750 \mathrm{PCU} / \mathrm{hr}$.

\section{ESTABLISHMENT OF LEVEL OF SERVICE (LOS)}

Urban road in developing countries carries heterogeneous traffic and do not follow any lane discipline. To study behavior of different types of traffic and their effect on the quality of travel, field data was collected at a selected stretch of Ahmedabad city.Volume to Capacity ratio is determined for the stretch and graphs of V/C vs speed are plotted. The highest and lowest speed observed on the upside curve are divided into equal intervals of speed for defining LOS. LOS ' $A$ ' to LOS ' $F$ ' has been defined from the graphs, which gives different ranges of $\mathrm{V} / \mathrm{C}$ ratio and speed for defined LOS. The downward curve represents LOS ' $F$ '. Also observed LOS criteria are compared with existing LOS criteria given in Indo
HCM. Level of service criteria has been determined based on observed traffic condition for individual direction, irrespective of that single LOS criteria is to be determined for an individual stretch. For overcoming this, the average values of both travel speed and $\mathrm{V} / \mathrm{C}$ are taken and criteria for LOS have been defined. Level of service criteria determined for selected stretches are different from LOS criteria recommended in INDO HCM. The speed-flow curves determining LOS are shown in Fig. 7 and 8 below. Also the actual LOS observed for all the selected stretches is to be compared with existing LOS criteria. In the present study nominal variations for $\mathrm{V} / \mathrm{C}$ is observed for $\operatorname{LOS}$ ' $\mathrm{A}$ ' and $\operatorname{LOS}$ ' $\mathrm{B}$ ' and also high variations are observed in V/C for LOS ' $\mathrm{C}$ ' and LOS ' $D$ '. The variation in the static and dynamic characteristics of the vehicles is converted in a common unit called PCUs and estimation of Level of Service is done. The comparison of ranges of $\mathrm{V} / \mathrm{C}$ and speed with the suggested ranges in INDO HCM are shown in Table 6 mentioned below.

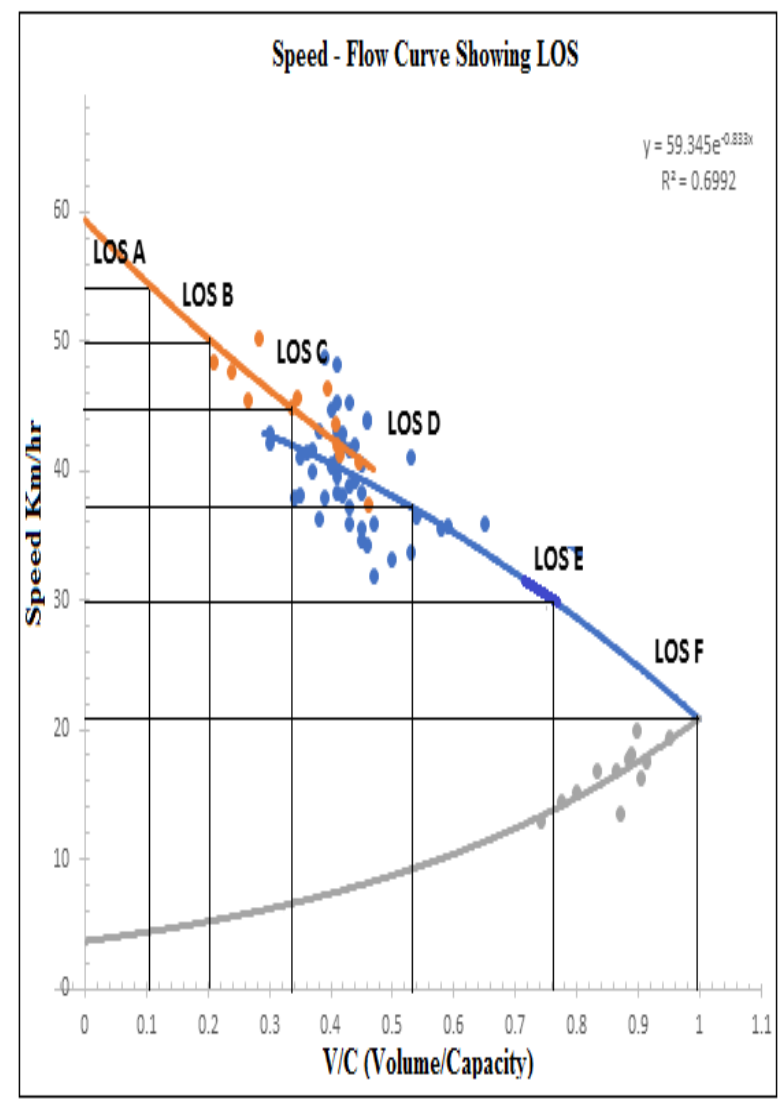

Fig 7. Speed-Flow Curve showing LOS (Towards Tapovan Circle) 


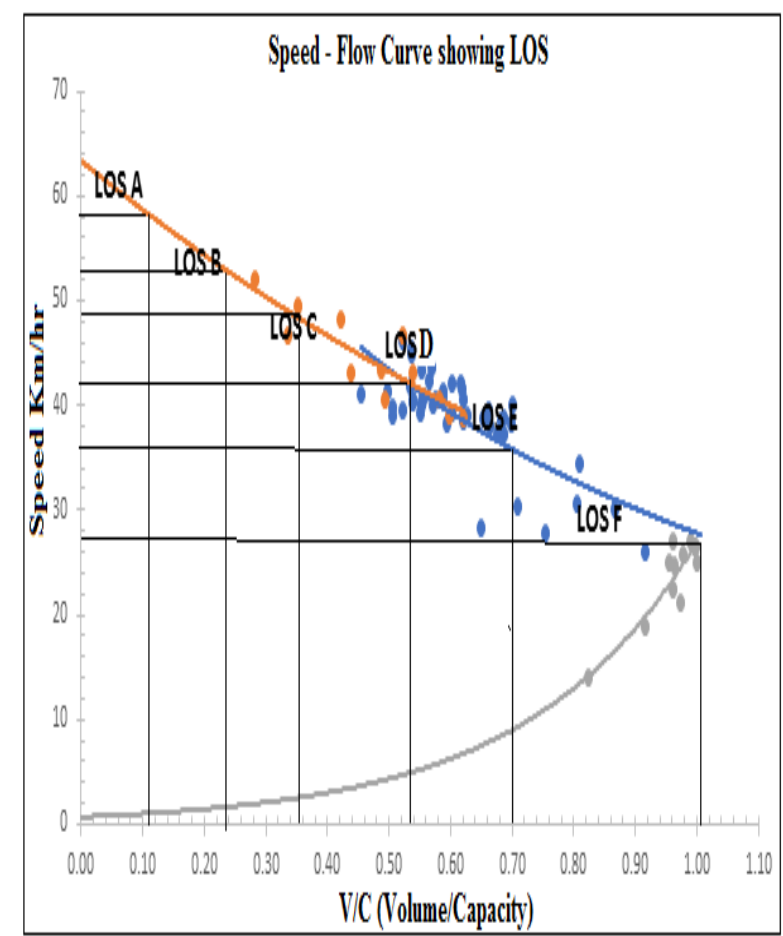

Fig 8. Speed-Flow Curve showing LOS (Towards ONGC Circle)

Table 6. Comparision of Suggested LOS (INDO HCM) vs Proposed LOS

\begin{tabular}{|c|c|c|}
\hline & & $\begin{array}{c}\text { Arterial Road } \\
\text { (Six Lane } \\
\text { Divided) }\end{array}$ \\
Sevel of & V/c ratio as per & \\
\cline { 3 - 3 } INDO HCM & V/C Ratio \\
\hline LOS A & $<0.15$ & $<0.12$ \\
\hline LOS B & $0.15-0.45$ & $0.12-0.27$ \\
\hline LOS C & $0.46-0.75$ & $0.28-0.42$ \\
\hline LOS D & $0.76-0.85$ & $0.43-0.61$ \\
\hline LOS E & $0.86-1$ & $0.62-0.80$ \\
\hline LOS F & $>1$ & $>1$ \\
\hline
\end{tabular}

\section{SUMMARY AND CONCLUSION}

Following are the important conclusions that are drawn from the present study.

- For the selected stretches, the difference in V/C recommended by INDO-HCM and suggested $\mathrm{V} / \mathrm{C}$ for $\mathrm{LOS}$ ' $\mathrm{A}$ ' is $20 \%$ for Arterial road.

- The difference in $\mathrm{V} / \mathrm{C}$ recommended by INDOHCM and suggested V/C for LOS ' $\mathrm{B}$ ' is in the range of $20 \%$ to $40 \%$ for Arterial road.

- The difference in $\mathrm{V} / \mathrm{C}$ recommended by INDO$\mathrm{HCM}$ and suggested $\mathrm{V} / \mathrm{C}$ for LOS ' $\mathrm{C}$ ' is in the range of $40 \%$ to $44 \%$ for Arterial road.
- The difference in V/C recommended by INDO$\mathrm{HCM}$ and suggested V/C for LOS ' $\mathrm{D}$ ' is in the range of $29 \%$ to $44 \%$ for Arterial road.

- The difference in V/C recommended by INDO$\mathrm{HCM}$ and suggested V/C for LOS ' $\mathrm{E}$ ' is $20 \%$ to $29 \%$ for Arterial road.

\section{FUTURE SCOPE}

(1) The estimated Level of Service criteria is based on traffic condition of arterial road of Ahmedabad city. This estimated criteria maybe applied to similar roads of Ahmedabad city.

(2) Model for estimation of Level of Service criteria should be developed for heterogeneous traffic condition.

(3) More number of parameters should be considered in the analysis other than the parameters mentioned in INDO HCM.

(4) It is suggested to carry out study on greater number of observations for model calibration.

(5) The results obtained from the present study can be compared with results of simulation software.

\section{REFERENCES}

[1] Arpit Sharma, Prof. N. G Raval, "Estimation of Level of Service for Heterogeneous traffic in urban area - A case study of Ahmedabad city." IJAERD, 2018

[2] Babit Robin, Sharma Viranta, Duggal Ajay K., "Level of Service concept in urban roads." IJESIRD, 2016.

[3] Bhavneet Singh, Dr. Tripta Goyal, "Study of Traffic Volume and Level of Service of Panjab University, Chandigarh." IJERA,2015

[4] Chisty Kutub Uddin, Islam Md. Ashraful, Misuk Shahjalal, "Determination of Level of Service of Agrabad to CEPZ Road at Chittagong in Bangladesh." World Academy of Science Engineering \& Technology, 2014

[5] C. V Yeramwar, A. A Kaley, K.M Bambode, "Estimation of Capacity and Level of Service of roads" - IJSRSET, 2016

[6] INDO HCM, "Indian Highway Capacity Manual" Central Road Research Institute, New Delhi, 2017

[7] IRC-106, "Guidelines for capacity of roads in urban area", Indian Road Congress, New Delhi, 1990.

[8] Manghat Drisya, Aswathy KV, Krishnamurthy Karuppanagounder, "Automobile Level of Service Criteria for Two-Lane Undivided Heterogeneous Urban Corridors." European Transport, 2017.

[9] M. Sangeeta, M.V.L.R. Anjancyulu \& M. Harikrishna, "Comparison of Level of Service measure for Two Lane Rural Highway in mixed traffic." ICETEST, 2018 
International Journal of Research in Advent Technology, Vol.7, No.5, May 2019

E-ISSN: 2321-9637

Available online at www.ijrat.org

[10] Patel Chetan R, Dr. Joshi G.J., "Capacity and LOS for urban arterial road in Indian mixed traffic condition." ELSEVIER, 2012.

BOOKS

[1] Kadiyali L.R.'Traffic Engineering and Transport Planning”, Khanna Publishers (2000)

[2] Saxena S.C.'Textbook of Highway and Traffic Engineering", CBS Publication.

WEB SITES

[1] www.google.com

[2] www.nptel.com

[3] https://en.m.wikipedia.org/wiki/Ahmedabad

[4] http://www.sutpindia.com/skin/pdf/Ahmedabad_ TMICC.pdf

[5] www.googlemaps.com 